\title{
Erratum to: Response of invertebrates from the hyporheic zone of chalk rivers to eutrophication and land use
}

\author{
Octavian Pacioglu $^{1,2} \cdot$ Oana Teodora Moldovan ${ }^{3} \cdot$ Peter Shaw $^{1} \cdot$ Anne Robertson $^{1}$
}

Published online: 14 January 2016

(C) Springer-Verlag Berlin Heidelberg 2016

Erratum to: Environ Sci Pollut Res

DOI 10.1007/s11356-015-5703-0

The list of co-authors was incorrect and 2 names were missing in the original publication of the paper. The complete Author list and affiliations are presented in this article.

The online version of the original article can be found at http://dx.doi.org/ 10.1007/s11356-015-5703-0.

$\triangle$ Octavian Pacioglu

o.pacioglu@qmul.ac.uk

Oana Teodora Moldovan

oanamol35@gmail.com

1 Centre for Research in Ecology, Department of Life Sciences, University of Roehampton, Holybourne Avenue, London SW15 4JD, UK

2 River Communities Group, Freshwater Biological Association, River Laboratory, Queen Mary University of London, East Stoke,

Wareham, Dorset BH 20 6BB, UK

3 "Emil Racovita" Institute of Speleology, Clinicilor 5, 400006 Cluj-Napoca, Romania 